the research worker in the particular areas covered. Thus, one is led to ask, first, for whom is this type of book intended and, second, does it fill a special need not already met by existing journals? The answer to the second question would seem to be that there are certain areas of botanical research not covered by specialist review journals, and that there is therefore a place for this series, with its very wide coverage. But the very breadth of the series creates its own problem, since it is unlikely that the reader will find more than one article in each volume lying within his own field, as compared with a review journal devoted to a particular branch of botany. Consequently, if this series is to serve more than a small band of specialists, most of the articles will also have to be intelligible to the non-specialist reader who wishes to read further within, or outside, his own branch of botany, and the subjects will have to be chosen for their appeal to a reasonably wide audience.

This plea for a little more consideration for the nonspecialist reader should not obscure the fact that all the papers in this volume are of a very high quality and that it can confidently be recommended as a valuable contribution to current botanical thought.

\section{P. F. WAReing}

into these important problems of parasitology. The strict separation of chapters sometimes prevents a continuous discussion of biochemical specialization in one parasitic group-oxidative metabolism in the trypanosomes, for example. In its present form the book is therefore of greater use to the experienced research worker than the young student.

A survey as extensive as this also serves as a comment on the present state of biochemical parasitology. It indicates that most of the work has been carried out on a small number of organisms, chiefly malaria parasites, trypanosomes, trichomonads, cestodes and nematodes. Three chapters devoted to carbohydrate biochemistry also indicate the unevenness of the development of metabolic studies on parasites. Dr. von Brand can report little advanced work on the biosynthesis of macromolecules, which occupies the attention of biochemists in other fields. Such studies have been hampered by the difficulties of parasite isolation and maintenance, but the problems are not insurmountable.

In conclusion one can say that this is the only recent book which deals adequately with the biochemistry of all groups of parasitic animals. No errors of fact are to be found in the text, and the index, although not especially exhaustive, is generally adequate.

\section{D. Ginger}

\title{
MOLECULAR PARASITOLOGY
}

\section{Biochemistry of Parasites}

By Theodor von Brand. Pp. ix +429 . (New York: Academic Press, Inc.; London: Academic Press, Inc. (London), Ltd., 1966.) 128s.

THIS book is not simply a revision of the previous edition (1952), entitled Chemical Physiology of Endoparasitic Animals, for it has been rewritten with the shift of emphasis indicated by the new title. By combining all aspects of biochemical structure and function of each chemical class into a single chapter, the number of chapters has been reduced from twenty to nine. As well as three chapters devoted to carbohydrates, there are separate chapters on inorganic substances, lipids, proteins, nucleic acids, vitamins and respiration. The inclusion of nucleic acids indicates the advances in this field since 1952, while the chapter in the first edition entitled "Miscellaneous Physiologically Active Substances" becomes the basis of the present chapter on "Vitamins". Much information of a physiological nature, such as osmotic relationships and endocrinology, has been omitted from the present volume. The dispersal of information previously contained in the section "The Biochemical Basis of Chemotherapy" may be a mistake, for such a chapter would be more in line with the compact style of the current edition.

Inevitably, because of the rapid accumulation of knowledge in recent years, the size of the book has increased by almost ninety pages, even though much early work has been omitted where superseded by more recent investigations. The biochemistry of the host-parasite relationship is well dealt with in the new volume, but each topic is included in the appropriate chapter and does not form a separate section as before.

Dr. von Brand's personal experience in much of the work has enabled him to extend the usefulness of the biochemical evidence by pertinent references to related work in the fields of histochemistry, cytochemistry and electron microscopy. There are also many practical tips, such as the use of enzymes for glucose estimation (p. 46) and criteria for the inhibition of enzymes by drug action (p. 177). 'The book is almost overflowing with well documented facts, and relevant data have usually been condensed into useful tables. Even so, the addition of a short section at the end of each chapter, or even of a separate chapter, discussing biochemical adaptations to a parasitic existence would have provided a better insight

\section{MICRO-ORGANISMS TO ORDER}

\section{Theoretical and Methodological Basis of Continuous} Culture of Micro-organisms

Edited by Ivan Málek and Z. Fencl. Translated by J . Liebster. Pp. 655. (Prague : Publishing House of the Czechoslovak Académy of Sciences; New York and London: Academic Press, 1966.) 208s.

THus book is really a series of critical essays on many aspects of the continuous culture of micro-organisms. Inevitably there is some overlap between them. The range covered is wide and, indeed, in the introduction Academician Málek writes: "It is the aim of this monograph to lay firm foundations for the wide application of the continuous cultivation method in microbiological, biochemical, genetic and cytological research and a basis for progress of the fermentation industries". This it does admirably.

Málek prepares the way for his colleagues and also gives a historical account of the development of continuous processes including multi-stage systems. He then looks to the future. J. Ričica deals with the various techniques in considerable detail and $\mathrm{K}$. Beran discusses their application to many problems in pure and applied research. $\mathrm{Z}$. Fencl analyses fully the underlying mathematical theory, while M. Burger focuses his attention on the occurrence of mutations in chemostat systems. Pathogenic organisms are also dealt with and the advantages of continuous cultivation, not only for the production of vaccines, etc., but also in fundamental studies, are pointed out (A. Stejskal). Techniques suitable for the growth of algae and animal cells and for use in soil microbiology are next examined (R. ̌̌tovský, M. Pospíšll, J. Macura). Finally, J. Hospodka considers industrial applications in detail.

The book contains a wealth of practical details pertinent to the construction and operation of suitable apparatus and a very comprehensive bibliography. The translation is adequate, but the legends for Figs. 5.2-1 and 5.2-3 have been interchanged and there are some typographical errors in Fencl's equations. (A list of corrections has been issued but is not, unfortunately, distributed with the book.) Although the price is high, this work should prove invaluable to anyone engaged in the study and the application of continuous processes either in the laboratory or in industry. A. C. R. Dean 